\title{
REPENSANDO A UNIVERSIDADE E AS TECNOLOGIAS DA INFORMAÇÃO E DA COMUNICAÇÃO
}

\author{
Maria de Fátima Monte Lima ${ }^{1}$
}

Resumo: Este artigo realiza a reflexão da relação universidade, conhecimento e as Tecnologias da Informação e da Comunicação, situando-a no contexto das mudanças ocorridas nos diferentes tempos históricos. Também aborda a sua configuração na Revolução Industrial, em que o trabalho manual era uma categoria central, e na contemporaneidade, com a revolução da microeletrônica, quando o trabalho intelectual passa a ser centralidade. A Revolução Industrial trouxe a invenção de novos artefatos que conduziu ao avanço da imprensa e a luta pela universalização do conhecimento e da informação. A revolução da microeletrônica trouxe com a presença das tecnologias digitais a luta pela universalização e democratização das tecnologias e do conhecimento pela possibilidade de acesso as redes digitais por meio de políticas de infraestrutura e de educação e comunicação. A cultura se torna mercadoria e a relação conhecimento e produção se aprofunda trazendo para interior da universidade pública uma grande contradição: aquela referente à inserção subordinada no processo de produção em geral, como ocorre com qualquer trabalho, no capitalismo, e aquela ligada à função de mediação, pelo fato de se tratar de produção de sentido. A reflexão da função secular da universidade e do conhecimento em um mundo que nos desafia com o espectro da exclusão social são inadiáveis.

Palavras-chaves: Universidade. Trabalho intelectual. Tecnologias da Informação e da Comunicação.

Abstract: This article presents a reflection of the university, knowledge and information technology and communication, placing it in the context of 
changes in different historical times. The setting in the industrial revolution, in which manual labor was a central category and, in contemporary times, with the microelectronics revolution, when the intellectual work becomes central. The industrial revolution brought the invention of new artifacts that led to the advancement of the press and the fight for the universalization of knowledge and information. The microelectronics revolution has brought to the presence of digital technologies to fight for the universalization and democratization of technology and knowledge through access to digital networks through policies on infrastructure, education and communication. The culture becomes a commodity and for knowledge production and deepens bringing within the public university, a great contradiction that on the subordinate position in the production process in general, as with any job, in capitalism, and that related to the role of mediation, because it is the production of meaning. The reflection function of the University and secular knowledge in a world that challenges us with the specter of social exclusion can not be postponed.

Keywords: University. Intellectual works. Information technology and communication. 


\section{Introdução}

As transformações trazidas com os avanços tecnológicos na microeletrônica geram mudanças qualitativas no mundo do trabalho e da cultura, exigindo, portanto, reflexão crítica. A temática da centralidade do trabalho intelectual em detrimento do trabalho manual como na sociedade industrial é tecida, justamente, no limiar do século XXI, quando a fragmentação do conhecimento, historicamente, se expressa de modo amplo, tornando-se uma tônica que fundamenta grande parte dos discursos educacionais e econômicos. O tempo é da informação e do conhecimento. Como consequência, Adorno (1995) entende que as transformações implicam em uma preocupação com o devir. Rigal (2000) adverte que não só cada sociedade tem seu próprio tempo, mas também dentro dela convivem e superpõem-se tempos diferentes, temporalidades. Se pensarmos na relação universidade/sociedade, entenderemos ser esta uma instituição social e, portanto, historicamente determinada por uma sociedade também datada, com suas temporalidades, como bem coloca Rigal (2000). Se nos remetermos à sua origem na Idade Média, no século XI, esta surge no seio das catedrais trazendo consigo as marcas das transformações de sua época e de todas aquelas que distam do início dos séculos XX e XXI, entre elas a Revolução Industrial e a revolução da microeletrônica.

Na perspectiva do conhecimento, a decadência da escola clássica e a formação da escola cristã foram processos que legitimaram as transformações da Idade Média, quando o conhecimento era patrimônio dos reis e do clero, podendo-se afirmar que a Igreja medieval exercia o monopólio do conhecimento que na Idade Moderna passa a ser monopólio do Estado. Nos séculos VIII e 
XIX, Carlos Magno inicia um movimento de fortalecimento do conhecimento melhorando as escolas, bibliotecas existentes nos conventos. Os estudos antes realizados nas catedrais foram cada vez mais se transformando em centros de estudos profundos passando a educação a ser uma questão de dois polos fortes de poder: o Estado e a Igreja. Nos séculos X e XI, com a queda da hegemonia carolíngia, a educação passou, então, para a égide da Igreja, iniciando um processo de laicização. No século XI também as transformações impulsionadas na economia com o avanço do comércio e com o surgimento da burguesia, inclusive reivindicando a instrução, ou seja, "[...] a fundação da universidade equivaleu a 'outorga de uma nova carta de franquia à burguesia." (MANACORDA, 1989, p. 99).

O desenvolvimento das universidades, segundo (BURKE, 2003), resultou da crescente divisão do trabalho associada ao surgimento das cidades. "A maioria dos professores e alunos das universidades era constituída por membros do clero, muitas vezes religiosos, principalmente dominicanos que contavam com o mais famoso dos professores medievais, Tomás de Aquino." (BURKE, 2003, p. 28). O século XII avança determinando que as escolas tanto dos mosteiros quanto das paróquias e catedrais recebessem alunos pobres e que não cobrasse para dar a licencia docenti (MANACORDA, 1989, p. 144). O aumento de estudantes no século XVI e início do século XVII resultou, em parte, da nova função da universidade como instituição de treinamento para o clero das paróquias, e também da crescente demanda dos governos por funcionários de direito (BURKE, 2003, p. 29). A função da universidade era meramente de transmissão do conhecimento com poucos olhos para a inovação. Neste século, o monopólio da educação superior foi posto em questão pelo surgimento dos institu- 
tos de pesquisa e pelo envolvimento dos letrados com os projetos de reforma econômica, social e política - Iluminismo. De acordo com Burke (2003), as universidades pouco contribuíram para o avanço da ciência no século XVII.

No caso do que chamamos de 'ciência' as inovações institucionais do século XVIII parecem ter tido importantes efeitos na prática das disciplinas. Mas é virtualmente inevitável que as instituições mais cedo ou mais tarde se cristalizem e se tornem obstáculos para inovações adicionais. Tornam-se lugares de interesses próprios, povoados por grupos que investiram no sistema e temem perder seu capital intelectual. (BURKE, 2003, p. 53).

\section{Revolução Industrial e universidade}

Historicamente, a expressão Revolução Industrial é usada para referir-se às mudanças ocorridas na organização e produção industrial iniciada na Inglaterra a partir de meados do século XVIII e caracteriza-se pela passagem da manufatura à indústria mecânica, que começa a realizar a produção em série, fundamentada na força de trabalho livre, assalariada de um lado e nos meios de produção dispostos pelos capitalistas.

Segundo Lima (2007), esta nova forma de produção social instituiu um processo de reeducação do homem, mudando o movimento vital de sua atividade produtiva para outro ritmo exterior a si próprio, artificial, impingido pela tecnologia - o da lógica da atividade industrial. A divisão social do trabalho, centrada em uma única ideia-atividade, inicia um processo de deslocamento entre o trabalho e o conhecimento, ainda elementar na antiguidade, evidenciado pela separação do saber, da arte e da cultura dos seus 
produtores. Essas formas vão se tornando hegemônicas. O capital industrial foi o responsável por este movimento, na medida em que provocou a desapropriação do conhecimento dos artesãos e articulou-o ao conhecimento decorrente do desenvolvimento científico que se dava no campo intelectual, transformando mestres em patrões e os aprendizes em empregados.

Sob outro olhar, Santaella (1997) faz uma análise da relação homem-máquina de acordo com a época em que cada tecnologia surgiu e classifica esta relação em três níveis: o muscular-motor, o sensório e o cerebral. As máquinas musculares a que a autora se refere fazem parte do século XIX, quando teve início a Revolução Industrial e estas eram movidas a vapor e, posteriormente, a eletricidade. Reproduziam os movimentos humanos com maior rapidez e maior força física, amplificando a capacidade humana uma vez que “[...] a Revolução Industrial foi uma revolução eletromecânica, [...] cuja potência não poderia ir além da imitação dos gestos humanos mais grosseiros e repetitivos." (Santaella, 1997, p. 35). As máquinas musculares produziam apenas artefatos e objetos industrializados.

Além das máquinas musculares, no contexto da Revolução Industrial foram criadas também as máquinas sensoriais, que, conforme McLuhan (1995), os meios de comunicação funcionam como extensão dos sentidos humanos, como a visão e a audição, produzindo ou reproduzindo signos e imagens. Por último, na revolução da microeletrônica foram criadas as máquinas cerebrais, que, para Santaella (1997), são a representação do pensamento humano, com toda a sua complexidade. Esta autora conclui que se as máquinas musculares amplificam a forma e o movimento físico humano e as máquinas sensoriais dilatam o poder dos sentidos, as máquinas cerebrais amplificam habilidades mentais, notadamente as processadoras e as da memória (Santaella, 1997, p. 41). 
As TIC máquinas proposicionais disponibilizam novos espaços e ambientes conhecidos também como ciberespaço. Para Trivinho (2000, p. 180), “[...] o conceito de ciberespaço diz respeito a uma estrutura infoeletrônica transnacional de comunicação de dupla via em tempo real, multimídia ou não, que permite a realização de trocas." Lévy (1999) considera o ciberespaço, ou rede, não apenas a infraestrutura informática, mas também as relações entre as pessoas que interagem neste ambiente. A interação entre as pessoas no ciberespaço cria novas formas de comportamentos, de linguagem, de atitudes, de valores, de práticas e costumes que este autor denomina de cibercultura.

Entretanto, o avanço nas forças produtivas não modificou a essência do modo de produção capitalista, como é o caso da revolução da microeletrônica. Tal processo que desconsidera o mundo a partir do homem, enquanto ser, continua a percebê-lo, enquanto força produtiva, como mercadoria. Acreditou-se que o progresso técnico, em detrimento da barbárie, conduziria para um mundo em que o desenvolvimento acelerado das forças produtivas brindaria os homens com relações de trabalho mais civilizadas. Estes não precisariam despender energia e saúde na execução de atividades desumanas, que passariam a ser realizadas por máquinas, inclusive, as mais sofisticadas e poderosas, que viriam a substituir também, por fim, tarefas mais sutis. Liberto da escravidão do trabalho mecânico e não das relações de exploração, o homem parecia ter suas horas livres ocupadas com atividades mais subjetivas, sensíveis e criativas que o fariam sentir-se mais realizado.

Entretanto, Lima (2007) afirma que a modernidade legou-lhe a racionalidade científica, erigida sobre a preponderância da razão, com seus fundamentos de verdade e de certezas, frente às demais formas de conhecimentos, ao primar pelo controle do homem so- 
bre o outro. Esta lógica elegeu a manipulação e a disciplina como formas por excelência de repressão e de vontade de poder. Um tipo de conhecimento e de vida que ao polarizar a existência teceu uma armadilha contra a capacidade criadora.

A abstração vai, cada vez mais, caracterizando o projeto da modernidade, afastando, gradativamente, o corpo de sua forma sensível de conhecer a realidade. Sob este legado, as práticas educativas voltadas para as habilidades operacionais e intelectuais têm ignorado a dimensão do saber sensível não sendo este sequer reconhecido como alguma forma de saber, de conhecimento. No projeto moderno, os corpos só devem existir para a inteligência e esta para a consciência moral. A racionalidade para a qual o mais importante é o interesse prático da Educação.

Fruto de uma separação bastante antiga entre as atividades intelectual e material. Isto quer dizer que significa não ser esta separação originária da modernidade. Sohn-Rethel (1995) demonstra a sua ligação direta com a existência da forma mercadoria generalizada e com a abstração real que a forma dinheiro expressa, surgindo, pela primeira vez na história, na Grécia antiga ${ }^{2}$. As reflexões acerca da ciência e da técnica, de certo modo, têm contribuído para tal modo de existir, contudo; também podem, inequivocamente, contribuir de alguma maneira, como analisou Marx, para a construção de uma racionalidade que não apenas aprofunde a barbárie humana, mas que venha a criar condições de liberação do homem. A Terceira Revolução Industrial cuja articulação básica entre ciência e tecnologia poderia propiciar possibilidades, e só possibilidades de mudança, demonstra alterações nos sustentáculos da vida produtiva, dispondo de outro modo a configuração mundial do trabalho. Entretanto, não se tem certeza do caráter generalizador dessas transformações tecnológicas e nem do seu potencial positivo. 
A universidade na contemporaneidade deve assumir uma função relevante, tanto na formação da cidadania quanto para a qualificação para o trabalho, uma vez que o trabalho docente remete-nos à necessidade de reconhecer a centralidade da categoria trabalho, bem como a função do trabalho intelectual na produção, na formação, na pesquisa e na difusão de conhecimentos científicos relevantes para a ciência e para a sociedade. Pois, certamente, as condições em que esse trabalho se realiza determinam o tipo de formação oferecida aos discentes e, consequentemente, a posição que a categoria ocupa na sociedade.

A relação entre educação, tecnologia e sociedade é uma questão que se coloca a todos aqueles que discutem a história do conhecimento, a Pedagogia e as relações sociais no mundo atual. A produção do conhecimento deve pautar-se na liberdade de expressão, autonomia do trabalho intelectual, legitimados, segundo Chauí (2001, p. 41), pelo princípio ético da racionalidade consciente e o princípio político de responsabilidades social uma ética. Pensar a universidade, a educação e a tecnologia é pensar a educação como espaço de sociabilização e a escola como um instrumento capaz de colocar as classes populares em contato com o conhecimento sistematizado, ao longo da história da humanidade e em condições de enfrentar um mercado de trabalho cada vez mais competitivo. Faz-se necessário, também, discutir a presença ou a ausência da tecnologia no mundo escolar, além das formas de utilização.

Nesse sentido é que

[...] observando a paulatina transformação da cultura em mercadoria e a intensificação da utilização dos meios de comunicação no sentido de empobrecer o conteúdo destinado à camada que de forma mais ou menos abstrata, recebe o 
rótulo de massa, Adorno e Horhkeimer preocupados com a questão do trabalho e da cultura defenderam a tese de que o homem se humaniza conforme o esclarecimento, isto é de acordo com o processo de racionalização historicamente construído que possui continuidade na filosofia e na ciência. (LIMA; BOLAÑO, 2001, p. 22).

Assim sendo, se faz necessária a reflexão crítica da universidade e da produção do conhecimento, na sociedade contemporânea, ligada às possibilidades colocadas pela reestruturação do capitalismo no século XXI. As TIC podem tornar-se um espaço virtual democrático, dialógico e contraditório. Uma rede de produção e de assimilação de saberes, de informações e de conhecimentos científicos constituída de poderes e, que, sob o controle do Estado e do capital, poderão confinar o componente criativo da esfera virtual, ao fechar portas e canais de acesso aos inúmeros e diferenciados criadores anônimos do cotidiano social.

Para Lima (2002), vista como fator de cultura, as TIC lançam o grande desafio da universalização e da democratização da educação, que cruzam as possibilidades políticas do Estado e da sociedade. Como fator de cultura, aprendizagem e democratização na escola, as redes digitais podem ser uma das oportunidades que a educação terá para reafirmar o seu lugar historicamente, libertando-se das amarras do tempo e espaço escolares circunscritos à normatização e regulação da razão instrumental, abrindo suas portas e janelas para a convivência com diferentes culturas na escola. O uso social das redes digitais pode, desde que socializada, transformar a escola única na escola plural, produzindo diferentes saberes, por e para diferentes culturas.

No entanto, os caminhos da sociedade como as suas possibilidades e limites são estabelecidos e construídos mediante os laços 
entre o Estado e a sociedade. Nesse universo, a discussão articula-se à das políticas educacionais e das TIC, uma vez que, originárias do processo de produção de mercadorias, surgem reorganizando o modo de produção e o trabalho abstrato, transformando a informação em elemento central do processo produtivo.

Se olharmos o passado não muito longínquo, encontraremos vários escritos em que o cenário educacional tem como tema central a educação e o desenvolvimento. Esta relação estabelece uma constante na formação das diferentes sociedades, colocando nos seus fundamentos a importância da inteligência e da competência humanas no desenvolvimento econômico dos diferentes modelos societais. No caso do modo de produção capitalista, a presença da universidade conectando ciência, trabalho e tecnologia é mais contundente, porque contraditória, uma vez que se exige, em sua dinâmica de acumulação primitiva da mais-valia, também, uma acumulação primitiva de conhecimento, por parte do capital. Isto tem ficado mais claro nas transformações dos diversos campos do conhecimento, provocadas pelo próprio processo de reestruturação capitalista, no final das duas últimas décadas do século XX, o qual vem colocando desafios em especial à educação, nas formas de participação, de produção e de socialização de conhecimentos.

\section{A centralidade do trabalho intelectual}

Dantas (1999) enfatiza o caráter ascendente do trabalho no movimento de acumulação contemporânea e, considerando sua natureza informacional, agregará valor na medida em que esse valor esteja contido na informação processada, registrada e comunicada. A centralidade atual do trabalho encontra-se ratificada por sua 
dimensão imaterial, promovendo-se uma rearticulação entre o trabalho manual e intelectual, configurando mais uma vez novas hierarquias, as quais evidenciam que na prática das relações de produção aprofundam-se os mecanismos de subordinação e de exclusão social, que explicitam, pelo contrário, a centralidade que o trabalho ainda possui. Assim,

[...] mais do que invadir a cultura, o capital torna-se cultura, no sentido mais amplo do termo, e a forma mercadoria passa a monopolizar o conjunto de relações sociais, inclusive aquelas mais internas e mais resistentes à expansão da lógica capitalista. (BOLAÑO, 2000, p. 48).

A qualidade da transformação atual é distinta das demais, porque o capital torna-se cultura e pela capacidade das TIC de trazê-la para o próprio modo de produção, em cujo âmago agora se situa, tornando fundamentais, por sua vez, os conflitos que se dão na esfera cultural, inclusive, pelo caráter mediador cultural que possui o trabalho intelectual diante da importância da cultura.

As TIC ao proporcionarem um processo de objetivação do trabalho intelectual trazem para o centro da produção a ciência e a tecnologia, e, o Estado busca formas alternativas que interfiram diretamente na elevação das taxas de maisvalia e de exploração através da produção de conhecimentos e de tecnologia adequadas de modo explícito. É, exatamente, nesse momento, que se concretiza, diretamente a articulação entre a ciência e o capital. Saltam-se aos olhos as ações que colocam a Educação num locus de centralidade, no âmbito do trabalho intelectual, enaltecendo os investimentos em pesquisa e na importância das inovações tecnológicas nas sociedades desenvolvidas. (LIMA, 2007).

Este papel central da Educação se reflete na função do ensino superior, determinando o surgimento de políticas que privilegiam 
uma perspectiva de qualificação para o trabalho, nos moldes exigidos pela sociedade capitalista, hoje. A universidade pública passa por uma ampla e complexa modificação que reorganiza o trabalho intelectual. Conforme Kawamura (1990), na esfera administrativa com a centralização e criação de instâncias de controle burocrático da produção científica e tecnológica (docente e discente) e com a departamentalização visando à racionalização dos recursos materiais e humanos. Expandem-se as áreas científico-tecnológicas, em inúmeras especializações, tanto para ensino quanto para pesquisa. A autora atenta ainda

[...] para a criação de novos órgãos técnicos e burocráticos, e reestruturados os já existentes, para a condução do planejamento educacional e a implantação das reformas de ensino, construindo-se uma extensa e complexa estrutura tecnocrática para administrar a realização dos planos de redefinição dos objetivos, dos currículos, dos métodos, da requalificação dos docentes e da reorientação dos discentes e egressos das escolas. O credenciamento de cursos passa pelo Ministério da Educação e da Cultura (MEC); além do fato de que tanto cursos quanto universidades são avaliados por pontos, visando estimular a concorrência no mercado da educação. Sob esse prisma, prioriza-se a técnica e a burocracia, passando a educação a ser mais uma questão técnica do que política (KAWAMURA, 1990, p. 32).

Assistiu-se, dessa forma, à “tecnificação" dos currículos, programas e disciplinas, bem como do próprio trabalho docente. As ações do governo em relação à educação e as TIC, analisadas por Lima (2002), apontam uma situação histórica de manutenção das desigualdades educacionais, ocorrendo mudanças apenas no sentido de modernizar a educação inclusive, paradoxalmente, de forma subdesenvolvida em relação à percepção das transformações 
culturais e tecnológicas advindas da reestruturação produtiva. Isto revela um novo lugar para o trabalho e a cultura e a escola (LIMA, 2002, p. 366-367).

Do ponto de vista internacional, o desenvolvimento de métodos pedagógicos baseados em novas tecnologias tem a finalidade de atender aos interesses de mercado para a produção tecnológica dos países centrais, uma vez que se utilizam dos aparatos e padrões tecnológicos por estes produzidos. A autora abaixo preocupa-se

[...] com o reforço aos padrões neoliberais que subordinam os conhecimentos à lógica do mercado e, portanto, a ausência do princípio democrático da autonomia e da liberdade de um lado, e da responsabilidade, de outro, uma vez que a utilização dos resultados científicos não é determinada pelos pesquisadores nem pelo poder público (CHAUÍ, 2001, p. 40).

São necessários aproximações e distanciamentos detectáveis, uma vez que se encontra em jogo concepções diferentes de sociedade e de educação, paradigmas distintos, modos diversos de objetivação, propostas pedagógicas díspares, modalidades variadas, contextos de aplicação específicos.

\section{A precarização do trabalho intelectual}

Em um contexto como esse, Miranda (2006) questiona até que ponto o professor é livre para executar e planejar seu trabalho, uma vez que

[...] caímos em situação análoga àquela que Marx se refere sobre a dupla liberdade do trabalhador: o professor possui 
uma dupla autonomia, que se expressa, por um lado, pela autonomia de exercer sua criatividade sem tempo para o planejamento, dada a intensificação de sua jornada, e por outro lado, a autonomia de planejar aulas com sua baixa qualificação, de fato. (MIRANDA, 2006, p. 43).

Na verdade, conforme ressalta a autora,

[...] o grau de autonomia do professor é cada vez menor, seja pela ampliação de sua jornada de trabalho, seja pelo rebaixamento de sua qualificação. A cristalização da imagem do professor como um sujeito pleno de autonomia, de exercício intelectual inalienável, oculta as origens históricas de seu processo de proletarização (MIRANDA, 2006, p. 45).

Oliveira (2007) observa com atenção a problemática e busca em Kawamura (1990) a devida explicação, quando esta atribui essa perda de autonomia à influência do conteúdo tecnicista da educação, que influi na reorientação da formação docente, tornando a prática profissional eminentemente técnica. Com a realização do planejamento curricular em instâncias superiores da burocracia educacional, resta ao docente o cumprimento dos programas nos prazos predeterminados. E a viabilidade disto repousa nos mecanismos de supervisão, controle e alteração operacionalizados por aquelas instâncias.

O professor torna-se assim um técnico com um conhecimento parcelar que deve dar conta de um trabalho docente também segmentado. Antes de se preocupar com a educação, ele precisa prestar conta dos programas e prazos através de extensos relatórios de atividades. $\mathrm{Na}$ realidade, a valorização do trabalho pedagógico tem como referência parâmetros técnicos e burocráticos em detrimento, muitas 
vezes, da formação propriamente dita do educando. Nessas condições, o aluno depara-se com uma colcha de retalhos, isto é, várias disciplinas de áreas diferentes, segmentadas e (des)articuladas entre si. (KAWAMURA, 1990, p. 44-45).

Em relação às propostas de educação baseada nas redes digitais, o planejamento sofre contradições, diante das condições deterioradas de trabalho educativo (carências materiais da escola e dos alunos; condições precárias do trabalho docente etc.). A produção teórica na área também deflagra uma série de questões. Alguns autores acabam por discutir tecnologia sem aprofundamento crítico do contexto em que elas surgem e outros sem o domínio efetivo do que é educação e muito menos Tecnologias da Informação e da Comunicação.

Expressões como cibernética, telemática, ciberespaço, Tecnologias da Informação e da Comunicação, internet, multimídia e virtualidade aparecem constantemente, com foco em seu uso no processo educacional, em detrimento da reflexão dos condicionantes econômicos, políticos e sociais, que determinam, inclusive, a progressiva inserção da tecnologia no cotidiano. Este, um assunto da maior importância, que não iremos desenvolver neste artigo por não ser este o nosso tema específico, mas é bom relembrar as palavras de Adorno (1995, p. 14) a este respeito, quando “[...] alerta os educadores para a necessidade da crítica permanente ao deslumbramento geral que a transformação da cultura em mercadoria provoca, em particular relativamente à educação, ameaçando o conteúdo ético do processo formativo em prejuízo da determinação social."

Para aprofundar a discussão, é preciso admitir a historicidade de problemas educacionais que não foram resolvidos ao longo 
de séculos e que contribuem para fossilizar a educação e a sala de aula, inclusive da universidade. Isto contrasta com o discurso muitas vezes futurista das salas de aula virtuais, quando a concepção mais tradicional de aprendizagem ainda não foi superada por outras proposições, que de fato atendam à construção de uma nova realidade. Discute-se a questão do acesso aos artefatos tecnológicos sem buscar compreendê-lo como parte de uma arraigada e pré-existente problemática sócio-político-econômica ${ }^{3}$.

Discute-se como o aluno usa estes artefatos esquecendo-se de que antes de saber usá-los é preciso saber ler o mundo, saber pensar e criar a partir dessa leitura, saber comunicar e registrar aquilo que se pensa. Investiga-se por que o aluno não aprende a usar a tecnologia, esquecendo-se que o aluno muitas vezes não sabe nem mesmo aprender, e quando se trata das camadas mais pobres da população mundial, como se vai aprender sobre um mundo de coisas ao qual não se tem acesso? E quando o acesso "chega" nem sempre os docentes estão preparados para realizar uma prática inovadora. Fala-se da capacidade de selecionar informações, com o advento da internet, esquecendo-se de levar em conta que a própria educação não forma uma massa crítica capaz de entender as mensagens subliminares que circulam na rede, engendradas pelo sutil processo de manipulação ideológica de que lançam mão os detentores do capital para garantir sua situação de hegemonia.

Oliveira (2007) questiona: como discutir tecnologia sem admitir as nossas exclusões sociocultural, intelectual e tecnológica? Sem admitir que não há como se apropriar destes artefatos criticamente se não soubermos ler, escrever, pensar, estudar, aprender criticamente? Como nos comunicar? E que, muitas vezes, falhamos ao considerar a incompetência do aluno como uma questão 
de mérito, esquecendo-nos de relacioná-la com as fragilidades da própria estrutura educacional, da nossa própria prática pedagógica, inserida na dinâmica social, econômica e política mais ampla?

Quando falamos das TIC, estamos nos referindo aos saberes e competências imprescindíveis ao processo de formação discente na contemporaneidade, portanto falamos de universidade hoje. Estamos falando da necessidade premente de que os educadores favoreçam em seus alunos a aquisição dos conhecimentos de diferentes temporalidades. Entretanto, os cursos de formação de educadores que abordam as tecnologias limitam-se apenas a descrever determinadas situações de aprendizagem, por meio de certos programas e aplicativos, sem considerar problemas como o da exclusão digital, que deixa uma grande parcela da população em posição de desvantagem com relação à minoria que tem amplo acesso aos artefatos tecnológicos, aprofundando o fosso entre as classes sociais. As TIC já estão sendo amplamente utilizadas pelas camadas mais privilegiadas da população. De acordo com Castells (1999, p. 55), “[...] as elites aprendem fazendo e com isso modificam as aplicações da tecnologia, enquanto a maior parte das pessoas aprende usando e, assim, permanecendo dentro dos limites do pacote da tecnologia." Não basta apenas disponibilizar o acesso à internet para consumir informação, o mais importante é usar as TIC para também produzir conhecimentos.

Nessa discussão, é imprescindível questionar em que medida a universidade responsabiliza-se pela formação dos professores, como tem instrumentalizado estes profissionais para o enfrentamento crítico dos problemas que perpassam a relação tecnologia-educação, na sociedade em que vivemos. Se, por um lado, as redes digitais possibilitam uma ampla visualização dos processos univer- 
sitários, por outro lado, é preciso reconhecer, com Miranda (2006), que o caráter do trabalho docente não pode ser interpretado como imbuído de uma força mística, imune à subordinação do capital.

\section{A subsunção do trabalho intelectual}

Pelo contrário, Lima e Bolaño (2001), em suas reflexões, já consideravam esse trabalho incorporado ao processo de acumulação capitalista, cuja lógica organizativa aponta dois delineamentos. $\mathrm{O}$ primeiro deles reside na tendência a um processo crescente de alienação do trabalho docente, com a perda de autonomia do professor, cujo trabalho encontra-se fragmentado por áreas e submetido a rígidos processos de controle. $\mathrm{O}$ segundo delineamento consiste na tendência à subsunção real ao capital, conceito já colocado.

O trabalhador intelectual vive a contradição de servir, na medida em que é obrigado a vender sua força de trabalho, para garantir a satisfação das suas necessidades humanas, historicamente determinadas, ao sistema de exploração, exclusão e violência do capital, ao mesmo tempo em que percebe que esse mesmo sistema restringe suas capacidades criadoras e o separa da imensa maioria dos seus semelhantes, condenados a condições de vida desumanas. (LIMA; BOLAÑO, 2001).

Há uma cobrança de produtividade semelhante à perversa lógica de mercado, e os professores tornam-se máquinas a serviço do sistema, distanciando-se cada vez mais do efetivo domínio do seu ofício: favorecer a aprendizagem do aluno. Sem aprendizagem efetiva, não pode haver qualquer produtividade em matéria de Educação. 


\section{Trabalhando a contradição}

Na realização do trabalho docente, os autores abaixo identificam o papel das redes digitais como elemento definidor, por causa de dois aspectos básicos, apontados pelos autores:

O primeiro, o trabalho intelectual é humano e isto dificulta uma subordinação total e completa aos ditames da produção de mercadorias, embora tudo seja feito para anulá-lo. Este seu caráter específico é o elemento necessário ao processo de mediação que dirigido para a legitimação das relações sociais capitalistas, abre possibilidades de ações liberadoras. O segundo, as Tecnologias da Informação e da Comunicação possuem o caráter generalizante da convergência o que as torna fator de produção do capitalismo globalizado. Estruturam-se de forma anárquica, apesar de se adequarem à hierarquia do sistema capitalista, o que favorece a construção de práticas sociais horizontais e de cooperação e solidariedade. (LIMA; BOLAÑO, 2006).

Contraditoriamente, as TIC, ao invadirem os diferentes espaços, chegam à academia, escola e demais espaços educativos da sociedade, oportunizando novos canais e formas de organização, de produção e de transmissão de conhecimentos, alargando o campo educativo, desde que socializadas. Tal movimento pode determinar a elaboração de diferentes formas de aprendizagem e de diferentes processos de sociabilidades, que dinamizam os saberes das diferentes culturas e classes sociais, reafirmando o papel de mediação do trabalho intelectual,

[...] o que lhe confere um caráter duplamente contraditório: aquele referente à inserção subordinada no processo de produção em geral, como ocorre com qualquer trabalho no capitalismo; e aquele ligado à função de mediação, pelo 
fato de se tratar de produção de sentido. (LIMA; BOLAÑO, 2001, p. 29).

Esta função de mediação e produção de sentidos gera, para o trabalho docente, o imperativo de reafirmar certa autonomia do trabalho intelectual, no sentido de na própria prática docente e de pesquisa (des)construir, construir, (re)construir novas práticas educacionais desnaturalizando a emergência das tecnologias, num processo crítico e interativo de constituição de uma outra produção coletiva. Nesta perspectiva, defendemos a relevância das TIC na visualização do processo de trabalho intelectual do docente universitário enquanto meio, aberto, de compartilhamento e construção coletiva de conhecimentos, jamais como instrumento hermético de controle e cooptação dos sujeitos a serviço de um modelo perverso e excludente de sociEDADE.

Ferreira (2004) advoga que o acesso de pessoas aos meios tecnológicos terá maior sentido se estiver articulado a um projeto de formação de cidadania, em que cada cidadão tenha a possibilidade de disponibilizar na rede conteúdos que possam contribuir para a construção do que Lévy (1994) chama de "inteligência coletiva”. Esta é entendida como uma “[...] inteligência distribuída por toda a parte, incessantemente valorizada, coordenada e mobilizada em tempo real, que resulta em uma mobilização efetiva das competências." (Lévy, 1994, p. 28). E reitera que, para este autor, esta inteligência somente poderá ser desenvolvida se baseada nas TIC, pois elas proporcionam "[...] aspecto participativo, socializante, descompartimentalizante, emancipador.” (LÉVY, 1999, p. 30).

É com este objetivo que algumas universidades, governos e organizações não governamentais (ONGs) têm disponibilizado à população o acesso às tecnologias digitais, pois a utilização 
das TIC pode potencializar a produção de conhecimentos com o envolvimento de múltiplos autores de maneira não linear, numa perspectiva de rede, em que cada nó pode ser o centro de outras redes que estão constantemente sendo alteradas interativamente. Porém, como já apontamos, as tecnologias capazes de proporcionar estas novas formas de relações não estão disponíveis à maioria da população mundial, elas se tornam possibilidades e somente possibilidades uma vez que nem todos os países têm condições econômicas e de poder para apropriar-se e utilizar-se do mesmo modo que os países mais avançados, tecnologicamente falando.

A implantação de espaços públicos que possam garantir o acesso às TIC para a população é uma importante medida a ser tomada pelos órgãos governamentais. Contudo, não basta apenas garantir o acesso, é necessário preparar as pessoas para se apropriarem das TIC e também de aprendizagens de maneira interativa e que lhes possibilitem ser algo mais que usuários de tecnologias ou consumidores de informações.

Não basta, contudo, apenas usar sites confiáveis para realizar uma boa pesquisa. É preciso saber o que fazer com os dados coletados, e para isso é imprescindível ter uma educação que possa orientar para a utilização das TIC não somente como fontes informativas ou como ferramentas auxiliares no processo pedagógico, mas como potencializadoras na construção de conhecimentos. Esses conhecimentos, elaborados a partir da rede e de outras discussões com professores e alunos, precisam retornar à web para que ela, além de ser uma grande fonte de informação, possa constituir-se em fator desafiador para a construção e troca de saberes.

As Tecnologias da Informação e da Comunicação são propiciadoras de processos como a virtualização, a hipertextualidade e a interatividade. 
Todavia, Lima (2002) afirma que sem criticidade as vantagens liberadoras das TIC jamais poderão ser desfrutadas e colocadas a serviço de um projeto de sociedade menos destrutivo e mais justo. Na visualização do processo de trabalho intelectual do docente universitário, as TIC só adquirem sentido na medida em que se tome este trabalho não só como uma mercadoria, mas como prática institucional capaz de contribuir para a emancipação dos sujeitos.

\section{Considerações finais}

A relação universidade, conhecimento e TIC carrega uma flagrante contradição em função de suas características intrínsecas e de sua história. A tensão entre os interesses comerciais que se expandem na rede e os interesses públicos é inequívoca. Matizam-se, naquela que poderia ser a ágora, velhas discussões ao mesmo tempo em que se reacendem as bases para o questionamento da democracia, a partir das possibilidades de interatividade. O crepúsculo do século XX demonstrou-nos que a história não acabou e que a centralidade do conhecimento surge como um dos diferentes caminhos no século XXI, mas que não se traduz em rupturas cruciais na economia instaurando uma democracia digital.

Nesse universo, o século XXI aponta mudanças significativas, do lugar da educação percebida por seu caráter de centralidade, como capital do novo século. No processo de produção de mercadoria, os caminhos da universidade e das TIC se cruzam por constituírem o campo do trabalho intelectual. $\mathrm{Na}$ perspectiva do mercado, as habilidades subjetivas são intensificadas no processo 
de aprendizagem em nome das "novas competências", a ideia de gestão tornou-se central aprofundando a lógica da divisão entre os que pensam e produzem.

Apesar da evidência de uma antiga dicotomia entre os diferentes poderes que cada instituição política e social representa e que não se dissolveu, mas é verdade que tomou mais visibilidade a partir das TIC, nos leva a pensar na possibilidade de tecermos socialmente novas ramificações nas áreas do social e do educacional, ampliando cada vez mais ações de universalização e democratização, viabilizadas pelas TIC. Reconhecer o lugar educativo cultural da universidade é perceber a educação e a universidade como campos culturais complexos e contraditórios de afirmativos processos de confrontação, desarticulação e rearticulação entre os diversos setores sociais em luta pela hegemonia.

\section{Referências}

ADORNO, Theodor W. Educação e emancipação. Rio de Janeiro: Paz e Terra, 1995.

BOLAÑO, César Ricardo Siqueira. Indústria cultural: informação e capitalismo. São Paulo: Hucitec/Polis, 2000.

Sociedade da informação, reestruturação produtiva e economia do conhecimento. Universidade e Sociedade: A contra-reforma universitária do governo Lula, Brasília, ano 14, n. 33, p. 186-190, jun. 2004.

- Trabalho Intelectual, Comunicação e Capitalismo: A reconfiguração do fator subjetivo na atual reestruturação produtiva. Revista da Sociedade Brasileira de Economia Política, Rio de Janeiro, n. 11, p. 53-78, dez. 2002. 
BRUNO, Lúcia. Educação, qualificação e desenvolvimento econômico. In: __ et al. (Orgs.). Educação e trabalho no capitalismo contemporâneo: leituras selecionadas. São Paulo: Atlas, 1996.

BURKE, Peter. Uma história social do conhecimento: de Gutemberg a Diderot. Rio de Janeiro: Jorge Zahar, 2003.

CASTELLS, Manuel. A sociedade em rede. São Paulo: Paz e Terra, 1999.

CHAUÍ, Marilena. Escritos sobre a Universidade. São Paulo: Editora UNESP, 2001.

DANTAS, Marcos. Capitalismo na era das redes: trabalho, informação e valor no ciclo da comunicação produtiva. In: LASTRES, Helena M. M.; ALBAGLI, Sarita (Orgs.). Informação e globalização na era do conhecimento. Rio de janeiro: Campus, 1999.

FERREIRA, Simone de Lucena. Um estudo sobre a interatividade nos ambientes virtuais da internet e sua relação com a educação: 0 caso da AllTV. 2004. Tese (Doutorado em Educação) - Programa de Pós-Graduação de Educação, Universidade Federal de Santa Catarina, Florianópolis, 2004.

KAWAMURA, Lili. Novas tecnologias e educação. São Paulo: Ática, 1990. (Série Princípios).

LÉVY, Pierre. Cibercultura. São Paulo: 34, 1999.

Inteligência coletiva: por uma antropologia do ciberespaço. São Paulo: Loyola, 1994.

LIMA, Maria de Fátima Monte. Educação e novas tecnologias: direito de todos! In: JAMBEIRO, Othon; BOLAÑO, César; BRITTOS, Valério (Orgs.). Comunicação, informação e cultura: dinâmicas globais e estruturas de poder. Salvador: Edufba, 2004. p. 176-187.

No fio de esperança: políticas públicas de educação, tecnologias da informação e da comunicação. 2002. Tese (Doutorado em Educação) - Universidade Federal da Bahia, Salvador, 2002. 
; BOLAÑO, César Ricardo Siqueira. Mundo do trabalho e educação a distância. Comunicação e Educação. Comunicação e Educação. São Paulo: Universidade de São Paulo, ano 7, n. 20, p. 21-32, jan./abr. 2001.

LIMA, Maria de Fátima M. Educação, movimentos sociais e produção de conhecimentos. In: III CONGRESSO ON-LINE, OBSERVATÓRIO PARA A CIBERSOCIEDADE. Movimentos sociais, políticas de inclusão e desenvolvimento na América Latina. Conhecimento aberto, sociedade livre. Anais eletrônicos... nov.-dez. 2006. Disponível em <http://www. cibersociedad.net/congress2006>. Acesso em: 22 dez. 2006.

MANACORDA, Mario Alighieri. Historia da Educação. São Paulo: Cortez, 1989.

McLUHAN, Marshall. Os meios de comunicação como extensão do homem. São Paulo: Cultrix, 1995.

MIRANDA, Kênia. O processo de trabalho docente: interfaces entre a produção e a escola. B. Téc. SENAC, Rio de Janeiro, v. 32, n. 2, p. 3849, maio/ago. 2006. Disponível em <http://www.senac.br/informativo/ bts/322/bts32 2-artigo4.pdf >. Acesso em: 2 dez. 2006.

OLIVEIRA, Andréa Hermínia de A. As tecnologias da informação e da comunicação e o trabalho intelectual docente na Universidade Federal de Sergipe. 2007. Dissertação - Universidade Federal de Sergipe, 2007.

SANTAELLA Lúcia. O homem e as máquinas. In: DOMINGUES, Diana (Orgs.). A arte no século XXI: a humanização das Tecnologias. São Paulo: Editora da UNESP, 1997.

SOHN-RETHEL. Trabalho espiritual e corporal: para uma epistemologia da história ocidental. 1995. Dissertação (Mestrado em Economia) - Universidade Federal da Paraíba, João Pessoa, 1995. Versão preliminar (mimeo.).

VERNANT, Jean Pierre. A origem do pensamento grego. São Paulo: Paz e Terra, 1990. 
TRIVINHO, Eugênio. A Epistemologia em ruínas: a implosão da teoria da comunicação no ciberespaço. In: MARTINS, Francisco Menezes; SILVA, Juremir Machado da (Orgs.). Para navegar no século XXI. 2. ed. Porto Alegre: Sulinas; Edipucrs, 2000.

\section{Notas}

${ }^{1}$ Professora doutora aposentada da Universidade Federal de Sergipe, professora colaboradora da Universidade Lusófona de Humanidades e Tecnologias. Pesquisadora na área de Educação e Comunicação e membro da Associação Latina Americana de Investigadores em Comunicação (ALAIC). E-mail: <serra_leoa@uol.com.br>.

${ }^{2}$ Sobre a história da racionalidade na Grécia antiga, conferir os estudos de Vernant (1990), que aporta uma contribuição exemplar, em especial, a obra A origem do pensamento grego.

${ }^{3}$ Ver dissertação de Oliveira (2007), apresentada ao Programa de Pós-Graduação da Universidade Federal de Sergipe e orientada pela Dra. Maria de Fátima Monte Lima. 
